\title{
Surviving sepsis: going beyond the guidelines
}

Paul E Marik

\begin{abstract}
The Surviving Sepsis Campaign is a global effort to improve the care of patients with severe sepsis and septic shock. The first Surviving Sepsis Campaign Guidelines were published in 2004 with an updated version published in 2008. These guidelines have been endorsed by many professional organizations throughout the world and come regarded as the standard of care for the management of patients with severe sepsis. Unfortunately, most of the recommendations of these guidelines are not evidence-based. Furthermore, the major components of the 6-hour bundle are based on a single-center study whose validity has been recently under increasing scrutiny. This paper reviews the validity of the Surviving Sepsis Campaign 6-hour bundle and provides a more evidence-based approach to the initial resuscitation of patients with severe sepsis.
\end{abstract}

Sepsis is among the most common reasons for admission to intensive care units (ICUs) throughout the world. During the past two decades, the incidence of sepsis in the United States has tripled and is now the tenth leading cause of death. In the United States alone, approximately 750,000 cases of sepsis occur each year, at least 225,000 of which are fatal $[1,2]$. Septic patients are generally hospitalized for extended periods, rarely leaving the ICU before 2-3 weeks. Despite the use of antimicrobial agents and advanced life-support, the case fatality rate for patients with sepsis has remained between $20 \%$ and $30 \%$ during the past 2 decades [1,2].

The Surviving Sepsis Campaign (SSC) is a global effort to improve the care of patients with severe sepsis and septic shock. The campaign was launched by the Society of Critical Care Medicine, the European Society of Intensive Care Medicine and the International Sepsis Forum in 2002. The first Surviving Sepsis Campaign Guidelines were published in Critical Care Medicine in 2004 and included 52 recommendations [3]. Ely Lily and Company and Edwards Life Sciences sponsored the guideline process, raising concerns about the integrity of the guidelines [4]. Furthermore, it appeared that the guideline implementation process was part of the marketing strategy for the Eli Lilly Company. The Surviving Sepsis Campaign Guidelines were updated in 2008, and although free of corporate sponsorship and somewhat broader in scope (85

Correspondence: marikpe@evms.edu

Division of Pulmonary and Critical Care Medicine, Eastern Virginia Medical School, Norfolk, VA 23507, USA

SpringerOpen ${ }^{\circ}$ recommendations), the core recommendation's remained largely unchanged [5].

These core recommendations were principally based on the results of a small, single-center study by Rivers et al. (Early Goal-Directed Therapy [EGDT]) whose validity has been recently under increasing scrutiny [6,7]. It is important to note that the majority of recommendations in both sets of guidelines were based on the lowest level of scientific evidence (Grade E - uncontrolled studies, case series and expert opinion). Barochia and colleagues performed a systemic review of the association between the component therapies of the Surviving Sepsis Campaign 6-hour resuscitation bundle and outcome [8]. These authors concluded that the "current sepsis bundles may force physicians to provide unproven or even harmful care. As administered and studied to date, only antibiotics meet the stated criteria of proof for bundle inclusion."

Evidence-based medicine is defined as "the conscientious, explicit, and judicious use of the best current scientific evidence in making decisions about the care of individual patients" [9]. The practice of evidence-based medicine means integrating clinical acumen with patients' unique clinical features and the best available external evidence from systematic research. Clinical practice guidelines embrace evidence-based medicine by rigorously distilling the highest level of evidence from the literature in an effort to help physicians to provide the best possible care to their patients. The principle construct of the guideline development process is that they should be evidencebased and not opinion-based, be fully transparent, and that the developers and sponsoring organization(s) should 
be free of significant conflict of interest. It is abundantly clear that the Surviving Sepsis Campaign Guidelines fail to meet these requirements for guideline validity. Regrettably, these guidelines have been endorsed by such organization as the "Institute of Healthcare Improvement" and the "Joint Commission" and have become regarded as the standard of care in the United States and many European counties. The Australian and New Zealand Intensive Care Society (ANZICS) have, however, questioned the validity of these guidelines. Due to concern that the guideline "package" would inappropriately be adopted by quality improvement programs and organizations, ANZICS have declined to endorse the Surviving Sepsis Campaign Guidelines [10].

It has become increasingly apparent that in many patients there is a long delay in both the recognition of sepsis and the initiation of appropriate therapy. This has been demonstrated to translate into an increased incidence of progressive organ failure and a higher mortality. Kumar and colleagues investigated the relationship between the duration of hypotension before antimicrobial administration in 2,600 patients with sepsis-induced hypotension [11]. They reported that the risk of dying increased progressively with time to receipt of the first dose of antibiotic. The Surviving Sepsis Campaign and EGDT have succeeded in putting the "spotlight" on sepsis and have popularized the concept that the early identification and treatment of sepsis is essential to improve the outcome of this potentially fatal disease. The early identification of sepsis, the early administration of appropriate antibiotics, and early hemodynamic resuscitation remain the cornerstone of the management of patients with sepsis. However, as demonstrated by Barochia and colleagues, the major components of the Surviving Sepsis Campaign 6-hour resuscitation bundle are not evidence-based and should be abandoned [8].

The hemodynamic alterations with sepsis are exceedingly complex and include volume depletion, depressed myocardial function, and altered microvascular flow. These changes are dynamic; it has been reported that patients with preserved ventricular function may progress to develop severely depressed contractility [12]. In addition, with progressive volume loading patients may develop severe tissue edema, which compromises tissue oxygenation. This paradigm dictates that that the hemodynamic profile of each patient be dynamically monitored and that therapeutic interventions may need be modified based on these changes [13]. Furthermore, it is evident that the complexity of these changes defies a simple treatment algorithm. The major elements of the "6-hour resuscitation bundle" of the Surviving Sepsis Campaign Guidelines include fluid resuscitation to achieve a central venous pressure (CVP) of $>8 \mathrm{cmH}_{2} \mathrm{O}$ (or $12 \mathrm{cmH}_{2} \mathrm{O}$ when on a ventilator) and a central venous oxygen saturation
$\left(\mathrm{ScvO}_{2}\right)>70 \%$ with the use of blood and inotropic agents. There is increasing recognition that the major elements of this bundle are not supported by scientific evidence $[8,10,14,15]$. Remarkably, these recommendations are based on a small $(n=263)$, nonblinded, single-center study (the River's EGDT study) [6], in which the lead author had significant undisclosed conflicts of interest and where the validly of the data has been questioned [7]. Furthermore, it is noteworthy that the reported hospital mortality of the standard therapy group in the River's EGDT study was $46 \%$; this compares to $17 \%$ in a recent randomized, controlled study that evaluated the outcomes of the 6-hour resuscitation bundle [16].

During the first hours of severe sepsis, venodilatation, transudation of fluid from the vascular space into the tissues, reduced oral intake, and increased insensible loss combine to produce hypovolemia [17]. Ventricular dysfunction and arteriolar dilation volume depletion contribute to impaired global perfusion and organ function. Treating hypovolemia is the most important component of the early management of severe sepsis. However, once the patient has received an adequate fluid challenge, further fluid challenges may not increase cardiac output and global perfusion [13]. Additional fluid may increase interstitial edema and further comprise the microvascular dysfunction that characterizes severe sepsis. The current paradigm of fluid management in patients with sepsis is one of adequate initial fluid resuscitation followed by conservative late-fluid management. Conservative late-fluid management is defined as even-to-negative fluid balance measured on at least 2 consecutive days during the first 7 days after septic shock onset. In a retrospective cohort study, Murphy and colleagues demonstrated that an approach that combines both adequate initial fluid resuscitation followed by conservative late-fluid management was associated with improved survival [18]. A retrospective analysis of the Vasopressin in Septic Shock Trial (VASST) demonstrated that those patients in the quartile with the largest positive fluid balance at both 12 hours and 72 hours had the highest mortality [19]. Additional studies have demonstrated that those patients who have the largest cumulative fluid balance have an increased mortality [20-22].

The optimal time to initiate vasopressor agents has not been rigorously studied. Many patients with severe sepsis will respond to a 2-L fluid challenge and require little additional hemodynamic support. If despite adequate intravascular filling a mean arterial pressure in excess of $65 \mathrm{mmHg}$ cannot be achieved, then vasoconstrictors must be used [23]. The early use of vasoconstrictors is recommended, because it reduces the incidence of organ failure and may prevent excessive volume overload (conservative late fluid management) [23]. Therefore, we recommend that a vasopressor agent (norepinephrine) be started once 
the patient has received $2 \mathrm{~L}$ of crystalloid (NS) [17,24,25]. In cases of life-threatening hypotension (i.e., diastolic blood pressure $<40 \mathrm{mmHg}$ ), treatment with vasopressors must be started immediately and concurrently with fluid resuscitation [23]. Norepinephrine (starting at $0.01 \mu \mathrm{g} / \mathrm{kg} /$ $\mathrm{min}$ ) should be titrated upwards while fluid resuscitation continues. Figure 1 provides an initial approach to the resuscitation of patients with septic shock; however, it is important to emphasize that these patients require close hemodynamic monitoring with dynamic changes as the hemodynamic course evolves. Ongoing fluid and vasopressor resuscitation should be guided by mean arterial pressure, pulse pressure variation, passive leg-raising maneuvers, urine output, oxygenation as well as cardiac output (determined noninvasively), and extravascular lung water measurement [13,26,27]. Bedside echocardiography is critical to determine left ventricular size and function. The central venous pressure (CVP) does not reflect intravascular volume nor does it predict fluid responsiveness and has no place in the resuscitation of patients with sepsis $[13,28,29]$. Interestingly, in the VASST study those patients who met the Surviving Sepsis Campaign CVP target had the highest mortality [19]. Although there is scant data to suggest that one vasopressor results in better outcomes than another (norepinephrine, epinephrine, vasopressin) [24,30-32], we favor norepinephrine as the first-line agent followed by dobutamine or epinephrine in patients with poor left ventricular (LV) function and vasopressin (fixed dose of $0.03 \mathrm{u} / \mathrm{min}$ ) in patients with "preserved" LV function and a low systemic vascular resistance (SVR; Figure 1). In patients with sepsis, norepinephrine increases blood pressure, as well as cardiac output, renal, splanchnic, cerebral blood flow, and microvascular blood flow while minimally increasing heart rate $[33,34]$. Norepinephrine seems to be the ideal first-line agent for the management of septic shock; additional agents should be considered in patients who remain hypotensive or display evidence of inadequate tissue or organ perfusion despite doses of norepinephrine up to $0.2 \mu \mathrm{g} / \mathrm{kg} /$ min. The second/third-line agents should be chosen based on the patient's hemodynamic profile as determined by $\mathrm{ECHO}$ and noninvasive assessment of cardiac output.

Dopamine has a number of theoretical disadvantages in patients with sepsis. It tends to increase heart rate, increases myocardial oxygen demand, and is associated with splanchnic mucosal ischemia. In addition, dopamine inhibits $\mathrm{T}$ and $\mathrm{B}$ lymphocytes and decreases secretion of prolactin, growth hormone, and TSH. In a large randomized, controlled trial, De Backer and colleagues compared dopamine with norepinephrine for the treatment of patients with shock [35]. In the subgroup of patients with septic shock, there was a trend toward improved outcome with norepinephrine; however, this difference did not reach statistical significance. A recent meta-analysis that compared norepinephrine to dopamine in patients with septic shock demonstrated a higher mortality with a significantly greater risk of arrhythmias with the use of dopamine [24]. Therefore, this drug should be avoided in patients with sepsis. Similarly phenylephrine is not recommended, because in experimental models it decreases cardiac output as well as renal and splanchnic blood flow [36]. Furthermore, these agents have not been rigorously tested in randomized, controlled studies.

EGDT and the Surviving Sepsis Campaign Guidelines call for the administration of a blood transfusion in patients' with a central venous oxygen saturation $\left(\mathrm{ScvO}_{2}\right)$ of less than $70 \%$ and a hematocrit of less than $30 \%$ (Grade $2 \mathrm{C}$ recommendation) $[3,5,6]$. This recommendation is a deviation from currently accepted transfusion practices, and as stated by Barochia and colleagues, this recommendation "may force physicians to provide unproven or even harmful care" [8]. In the critically ill, blood transfusions increase the risk of infections, acute respiratory distress syndrome (ARD), multisystem organ failure (MSOF), and death [37-39]. Although the intent of blood transfusions is to increase tissue oxygenation, blood transfusions paradoxically may have the opposite effect. Poorly deformable transfused red blood cells may impede microvascular flow [40]. Furthermore, the $\mathrm{P}_{50}$ of stored red cells may be as low as $6 \mathrm{mmHg}$ with the red blood cells being able to unload less than $6 \%$ of the carried oxygen; stored cell may thereby increase the $\mathrm{ScrO}_{2}$ (by binding oxygen) but compound the tissue oxygen debt by decreasing oxygen unloading.

Central venous oxygen saturation $\left(\mathrm{ScvO}_{2}\right)$ was used as the major endpoint of resuscitation in the intervention arm of the River' EGDT study (CVP $>8 \mathrm{cmH}_{2} \mathrm{O}$ was targeted in both the control and intervention groups) and is a Grade $2 \mathrm{C}$ recommendation in the Surviving Sepsis Campaign Guidelines [5,6]. This is problematic for a number of reasons [29]. Septic patients usually have a normal or increased $\mathrm{ScvO}_{2}$ due to reduced oxygen extraction [41,42]. A normal $\mathrm{ScvO}_{2}$ therefore does not exclude tissue hypoxia. A low $\mathrm{ScvO}_{2}$ is an important sign of inadequate oxygen delivery to meet systemic oxygen demands. However, it provides no information for the reason for this inadequacy, nor does it provide guidance as to the optimal therapeutic approach. It is noteworthy that in the Rivers study the mean $\mathrm{ScvO}_{2}$ was $49 \%$ with $65 \%$ of patients having a ScvO2 less than $70 \%[6]$.

No other sepsis study has reproduced this finding; the mean $\mathrm{ScvO}_{2}$ (on presentation) in most sepsis studies is approximately 70\% [43-45]. This suggests that other factors may have been in play to account for the low $\mathrm{ScvO}_{2}$ in the Rivers study $[15,46]$. These factors include the delayed presentation to hospital (possibly due to socioeconomic factors), greater number of patients with comorbid 


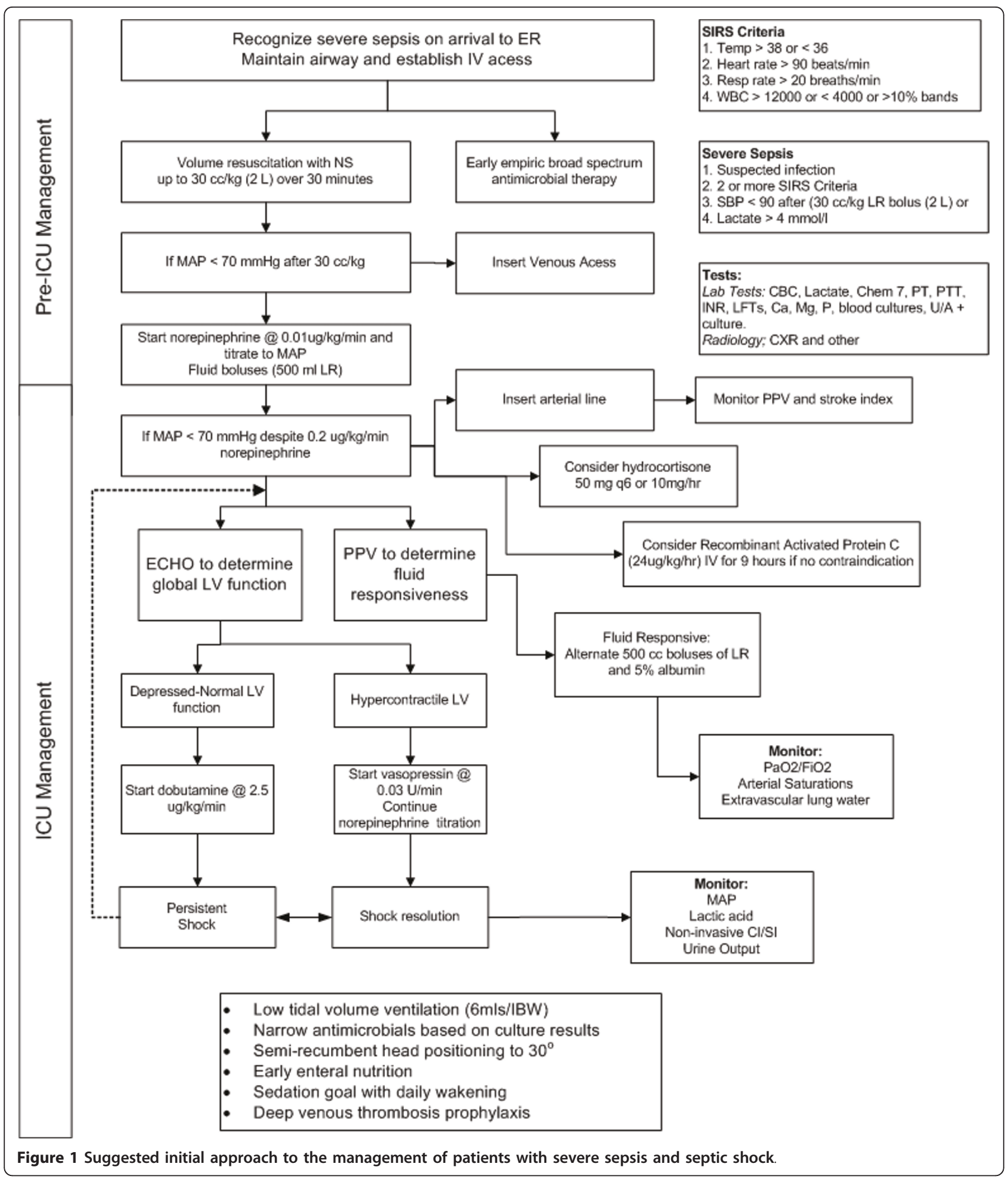

medical conditions, and a high incidence of alcohol use [15]. Thus, the combination of significant comorbidities (including heart disease) and a more delayed arrival of patients to the emergency department in the River's study may have led to a low cardiac output state, and in turn, to the very low $\mathrm{ScvO}_{2}$ values [44]. In a multicenter center EGDT study that enrolled 619 patients, Pope et al. reported that a high $\mathrm{ScvO}_{2}\left(\mathrm{ScvO}_{2}>90 \%\right)$ was an independent predictor of death [47]. In this study, a low initial $\mathrm{ScvO}_{2}\left(\mathrm{ScvO}_{2}<70 \%\right)$ was not predictive of mortality. 
Although aggressive early fluid resuscitation followed by vasoactive agents (in those with persistent hypotension) remains the cornerstone of the management of patients with severe sepsis and septic shock, the endpoints of resuscitation should be based on validated physiologic variables that are individualized based on each patients' comorbidities and unique clinical circumstances [13]. It is unlikely that a "one-size fits all" approach will be appropriate for all patients. A number of multicenter, randomized, controlled studies (ProCESS, ARISE) are currently being undertaken, which are testing the effectiveness of EGDT versus standard therapy [8]. These studies should aid in the development of an evidence-based approach to the early resuscitation of patients with severe sepsis and septic shock.

\section{Conclusions}

The past two decades have seen a remarkable growth in our understanding of sepsis and the complex interconnection of multiple biological pathways involved in the septic process. Despite initial enthusiasm with "disease-modifying agents," the early administration of appropriate antibiotics and early hemodynamic resuscitation remain the cornerstone of the management of patients with sepsis. This resuscitation of patients with sepsis should be based on the best current scientific evidence and coordinated by intensivists with expertise in managing these complex patients. Unfortunately, despite good intentions the Surviving Sepsis Campaign Guidelines are opinion-based rather than evidence-based and should be abandoned. Expert opinions are important but should be labeled as such and not be incorporated into evidence-based clinical practice guidelines.

\section{Competing interests}

The authors declare that they have no competing interests.

Received: 10 May 2011 Accepted: 7 June 2011 Published: 7 June 2011

\section{References}

1. GS Martin, DM Mannino, S Eaton, M Moss, The epidemiology of sepsis in the United States from 1979 through 2000. N Engl J Med. 348, 1546-1554 (2003). doi:10.1056/NEJMoa022139

2. DC Angus, WT Linde-Zwirble, J Lidicker, G Clermont, J Carcillo, MR Pinsky, Epidemiology of severe sepsis in the United States: analysis of incidence, outcome and associated costs of care. Crit Care Med. 29, 1303-1310 (2001). doi:10.1097/00003246-200107000-00002

3. RP Dellinger, JM Carlet, H Masur, H Gerlach, T Calandra, J Cohen, J GeaBanacloche, D Keh, JC Marshall, MM Parker, G Ramsay, JL Zimmerman, JL Vincent, MM Levy, Surviving Sepsis Campaign guidelines for management of severe sepsis and septic shock. Crit Care Med. 32, 858-873 (2004). doi:10.1097/01.CCM.0000117317.18092.E4

4. PQ Eichacker, C Natanson, RL Danner, Surviving sepsis: practice guidelines, marketing campaigns and Eli Lilly. N Engl J Med. 355, 1640-1642 (2006). doi:10.1056/NEJMp068197

5. RP Dellinger, MM Levy, JM Carlet, J Bion, MM Parker, R Jaeschke, K Reinhart, DC Angus, C Brun-Buisson, R Beale, T Calandra, JF Dhainaut, H Gerlach, M Harvey, JJ Marini, J Marshal, M Ranieri, G Ramsey, J Sevransky, T Thompson, S Townsend, JS Vender, JL Zimmerman, JL Vincent, Surviving sepsis
Campaign: International guidelines for management of severe sepsis and septic shock: 2008. Crit Care Med. 36, 296-327 (2008). doi:10.1097/01. CCM.0000298158.12101.41

6. E Rivers, B Nguyen, S Havstad, J Ressler, A Muzzin, B Knoblich, E Peterson, M Tomlanovich, Early goal-directed therapy in the treatment of severe sepsis and septic shock. N Engl J Med. 345, 1368-1377 (2001). doi:10.1056/ NEJMoa010307

7. TM Burton, New therapy for sepsis infection raises hope but many questions (lead article). The Wall Street Journal. (2008)

8. AV Barochia, X Cui, D Vitberg, AF Suffredinin, NP O'Grady, SM Banks, P Minneci, SJ Kern, RL Danner, C Natanson, PQ Eichacker, Bundled care for septic shock: an analysis of clinial trials. Crit Care Med. 38, 668-678 (2010). doi:10.1097/CCM.0b013e3181cb0ddf

9. DL Sackett, WM Rosenberg, JA Gray, RB Haynes, WS Richardson, Evidencebased medicine: what it is and what it isn't. BMJ. 312, 71-72 (1996)

10. P Hicks, DJ Cooper, S Webb, J Myburgh, I Seppelt, S Peeake, C Joyce, D Stephens, A Turner, C French, G Hart, I Jenkins, A Burrrell, The surviving sepsis campaign: International guidelines for management of severe sepsis and septic shock: 2008. An assessment by the Australian and New Zealand Intensive Care Society. Anaesth Intensive Care. 36, 149-151 (2008)

11. A Kumar, M Kazmi, D Roberts, K Wood, L Taiberg, D Feinstein, D Gurka, J Ronald, S Sharma, A Kramer, Duration of shock prior to antimicrobial administration is the critical determinant of survival in human septic shock. Crit Care Med. 32(Suppl):41 (2004). doi:10.1097/01.CCM.0000110735.30860.00

12. A Vieillard-Baron, V Caille, C Charron, G Belliard, B Page, F Jardin, Actual incidence of global left ventricular hypokinesia in adult septic shock. Crit Care Med. 36, 1701-1706 (2008). doi:10.1097/CCM.0b013e318174db05

13. PE Marik, X Monnet, JL Teboul, Hemodynamic parameters to guide fluid therapy. Annals of Intensive Care. 1, 1 (2011). doi:10.1186/2110-5820-1-1

14. PE Marik, J Varon, Early goal-directed therapy (EGDT): on terminal Ilfe support? Am J Emerg Med. 28, 243-245 (2010). doi:10.1016/j. ajem.2009.11.014

15. A Perel, Bench-to-bedside review: the initial hemodynamic resuscitation of the septic patient accordng to Surviving Sepsis Campaign guidelines-does one size fit all? Crit Care. 12, 223 (2008). doi:10.1186/cc6979

16. AE Jones, NI Shapiro, S Trzeciak, RC Arnold, HA Claremont, JA Kline, Lactate clearance vs central venous oxygen saturation as goals of early sepsis therapy: a randomized clinical trial. JAMA. 303, 739-746 (2010). doi:10.1001/ jama.2010.158

17. M Raghavan, PE Marik, Management of sepsis during the early golden hours. J Emerg Med. 31, 185-199 (2006). doi:10.1016/j.jemermed.2006.05.008

18. CV Murphy, GE Schramm, JA Doherty, RM Reichley, O Gajic, B Afessa, ST Micek, MH Kollef, The importance of fluid management in acute lung injury secondary to septic shock. Chest. 136, 102-109 (2009). doi:10.1378/chest.082706

19. JH Boyd, J Forbes, T Nakada, KR Walley, JA Russell, Fluid resuscitation in septic shock: a positive fluid balance and elevated central venous pressure increase mortality. Crit Care Med. 39, 259-265 (2011). doi:10.1097/ CCM.0b013e3181feeb15

20. F Alsous, M Khamiees, A DeGirolamo, Y moateng-Adjepong, CA Manthous, Negative fluid balance predicts survival in patients with septic shock: a retrospective pilot study. Chest. 117, 1749-1754 (2000). doi:10.1378/ chest.117.6.1749

21. JL Vincent, Y Sakr, CL Sprung, VM Ranieri, K Reinhart, H Gerlach, R Moreno, J Carlet, Sepsis in European intensive care units: results of the SOAP study. Crit Care Med. 34, 344-353 (2006). doi:10.1097/01.CCM.0000194725.48928.3A

22. Comparison of two fluid-management strategies in acute lung injury, $\mathrm{N}$ Engl J Med. 354, 2564-2575 (2006)

23. T Pottecher, S Calvat, H Dupont, J Durand-Gasselin, P Gerbeaux, Haemodynamic management of severe sepsis: recommendations of the French Intensive Care Societies (SFAR/SRLF) Consensus Conference, 13 October 2005, Paris, France. Crit Care. 10, 311 (2006). doi:10.1186/cc4658

24. TS Vasu, R Cavallazzi, A Hirani, G Kaplan, PE Marik, Norepinephrine or dopamine for septic shock: a systematic review of randomized clinical trials. J Intensive Care Med. (2011, in press)

25. PE Marik, J Lipman, The definition of septic shock: implications for treatment. Crit Care Clin. 9, 101-103 (2007)

26. PE Marik, R Cavallazzi, T Vasu, A Hirani, Dynamic changes in arterial waveform derived variables and fluid responsiveness in mechanically ventilated patients. A systematic review of the literature. Crit Care Med. 37, 2642-2647 (2009). doi:10.1097/CCM.0b013e3181a590da 
27. PE Marik, Techniques for assessment of intravascular volume in critically ill patients. J Intensive Care Med. 24, 329-337 (2009). doi:10.1177/ 0885066609340640

28. PE Marik, M Baram, B Vahid, Does the central venous pressure predict fluid responsiveness? A systematic review of the literature and the tale of seven mares. Chest. 134, 172-178 (2008). doi:10.1378/chest.07-2331

29. PE Marik, J Varon, Goal-directed therapy in sepsis. N Engl J Med. 346, 1025 (2002)

30. D Annane, P Vignon, A Renault, PE Bollaert, C Charpentier, C Martin, G Troche, JD Ricard, G Nitenberg, L Papazian, E Azoulay, E Bellisant, Norepinephrine plus dobutamine versus epinephrine alone for management of septic shock: a randomised trial. Lancet. 370, 676-684 (2007). doi:10.1016/50140-6736(07)61344-0

31. JA Myburgh, A Higgins, A Jovanovska, J Lipman, N Ramakrishnan, J Santamaria, A comparison of epinephrine and norepinephrine in critically ill patients. Intensive Care Med. 34, 2226-2234 (2008). doi:10.1007/s00134-0081219-0

32. JA Russell, KR Walley, J Singer, AC Gordon, PC Hebert, DJ Cooper, CL Holmes, S Mehta, JT Granton, MM Storms, DJ Cook, JJ Presneill, D Ayers, Vasopressin versus norepinephrine infusion in patients with septic shock. N Engl J Med. 358, 877-887 (2008). doi:10.1056/NEJMoa067373

33. MM Treggiari, JA Romand, D Burgener, PM Suter, A Aneman, Effect of increasing norepinephrine dosage on regional blood flow in a porcine model of endotoxin shock. Crit Care Med. 30, 1334-1339 (2002). doi:10.1097/00003246-200206000-00032

34. S Jhanji, S Stirling, N Patel, CJ Hinds, RM Perrse, The effect of increasing doses of norepinephrine on tissue oxygenation and microvascular flow in patients with septic shock. Crit Care Med. 37, 1961-1966 (2009). doi:10.1097/CCM.0b013e3181a00a1c

35. D De Backer, P Biston, J Devriendt, C Madl, D Chochrad, C Aldecoa, A Brasseur, P Defrance, P Gottignies, JL Vincent, Comparison of dopamine and norepinephrine in the treatment of shock. N Engl J Med. 362, 779-789 (2010). doi:10.1056/NEJMoa0907118

36. MB Malay, JL Ashton, K Dahl, EB Savage, SA Burchell, RC Ashton Jr, RR Sciacca, JA Oliver, DW Landry, Heterogeneity of the vasoconstrictor effect of vasopressin in septic shock. Crit Care Med. 32, 1327-1331 (2004). doi:10.1097/01.CCM.0000128578.37822.F1

37. PE Marik, HL Corwin, Acute lung injury following blood transfusion: Expanding the definition. Crit Care Med. 36, 3080-3084 (2008). doi:10.1097/ CCM.0b013e31818c3801

38. PE Marik, HL Corwin, Efficacy of RBC transfusion in the critically ill: A systematic review of the literature. Crit Care Med. 36, 2667-2674 (2008). doi:10.1097/CCM.0b013e3181844677

39. PE Marik, The hazards of blood transfusion. Br J Hosp Med. 70, 12-15 (2009)

40. PE Marik, WJ Sibbald, Effect of stored-blood transfusion on oxygen delivery in patients with sepsis. JAMA. 269, 3024-3029 (1993). doi:10.1001/ jama.269.23.3024

41. P Krafft, H Steltzer, M Hiesmayr, W Klimscha, AF Hammerle, Mixed venous oxygen saturation in critically ill septic shock patients. The role of defined events. Chest. 103, 900-906 (1993). doi:10.1378/chest.103.3.900

42. NK Liu, YP Zhang, WL Titsworth, X Jiang, S Han, PH Lu, CB Shields, XM Xu, A novel role of phospholipase A2 in mediating spinal cord secondary injury. Ann Neurol. 59, 606-619 (2006). doi:10.1002/ana.20798

43. PA van Beest, JJ Hofstra, MJ Schultz, EC Boerma, PE Spronk, MA Kuiper, The incidence of low venous oxygen saturation on admission the the intensive care unit: a multi-center observational study in the Netherlands. Crit Care. 12, R33 (2008). doi:10.1186/cc6811

44. PE Marik, A Bankov, Sublingual capnometry versus traditional markers of tissue oxygenation in critically ill patients. Crit Care Med. 31, 818-822 (2003). doi:10.1097/01.CCM.0000054862.74829.EA

45. NI Shapiro, MD Howell, D Talmor, D Lahey, L Ngo, J Buras, RE Wolfe, JW Weiss, A Lisbon, Implementation and outcomes of the Multiple Urgent Sepsis Therapies (MUST) protocol. Crit Care Med. 34, 1025-1032 (2006). doi:10.1097/01.CCM.0000206104.18647.A8

46. R Bellomo, MC Reade, SJ Warrillow, The pursuit of a high central venous oxygen saturation in sepsis: growing concerns. Crit Care. 12, 130 (2008). doi:10.1186/cc6841

47. JV Pope, AE Jones, DF Gaieski, RC Arnold, S Trzeciak, NI Shapiro, Multicenter study of central venous oxygen saturation $(\mathrm{SCvO}(2))$ as a predictor of mortality in patients with sepsis. Ann Emerg Med. 55, 40-46 (2010). doi:10.1016/j.annemergmed.2009.08.014 doi:10.1186/2110-5820-1-17

Cite this article as: Marik: Surviving sepsis: going beyond the

guidelines. Annals of Intensive Care 2011 1:17.

\section{Submit your manuscript to a SpringerOpen ${ }^{\mathcal{O}}$ journal and benefit from:}

- Convenient online submission

- Rigorous peer review

- Immediate publication on acceptance

- Open access: articles freely available online

- High visibility within the field

- Retaining the copyright to your article

Submit your next manuscript at $\boldsymbol{~ s p r i n g e r o p e n . c o m ~}$ 